\title{
Safety, Feasibility, and Efficiency of a New Cooling Device Using Intravenous Cold Infusions for Fever Control
}

\author{
J. F. Willms $\mathbf{2}_{2}$ O. Boss and E. Keller \\ UniversitatsSpital Zurich, Zurich, Switzerland
}

\begin{abstract}
Background: Fever control plays a key role in therapy of patients with acute brain injury. The infusion of cold saline could serve as an alternative or additional method for targeted temperature management. However, it is difficult to estimate the amount of fluid required to achieve normothermia merely on the basis of body weight. There is no standardized load management regarding the administration of cold saline, and no closed-loop systems based on continuous temperature-controlled feedback are available. The primary purpose of the present study was to evaluate the feasibility, efficacy, and safety of a new automated fluid infusion system.

Methods: Twelve patients with acute brain injury and febrile episodes were treated with the automated infusion device tempedy (seiratherm $\mathrm{GmbH}$, Herzogenaurach, Germany). Patients were included if bladder temperature still was $37.9{ }^{\circ} \mathrm{C}$ after administration of antipyretic medication, cold washing solutions, and ice packs more than $2 \mathrm{~h}$ earlier. The efficacy was examined by measuring the time and amount of fluid needed to reach and maintain target temperature. Feasibility and safety were assessed based on recording any technical difficulties with the new device and the occurrence of clinical signs of fluid overload such as acute pulmonary edema, electrolyte disturbances, or acid-base dysfunction.
\end{abstract}

Results: The mean time was $73 \mathrm{~min}$ (range from 15 to $330 \mathrm{~min}$ ) and $1650 \mathrm{ml}$ the mean amount of fluid $(21.2 \mathrm{ml} / \mathrm{kg}$; SD $28.5 \mathrm{ml} / \mathrm{kg})$ to reach the target temperature. The mean total fluid balance to reach and maintain the target temperature in the first $12 \mathrm{~h}$ was $1350 \mathrm{ml}$ (SD 1550 $\mathrm{ml}$ ). In the first $12 \mathrm{~h} 89.4 \%$ of the time temperature values were in the target range (median $95.3 \%$, range $83.8-10 \%$ ). No clinical signs of fluid overload such as an acute pulmonary edema or device-related adverse events occurred.

Conclusion: Target temperature management with the new automated infusion device is feasible. Although we pro- vided first data regarding safety, further controlled randomized studies are needed to evaluate the long-time safety, as well as the best indications and timing for this cooling device.

Keywords: Brain injury, Fever, Cold saline, Cold infusion, Targeted temperature management 


\section{Introduction}

Fever is common in patients with acute brain injury, and up to $90 \%$ develop a fever at least once within 7 days in the intensive care unit [1]. Regardless of its cause, it is linked to higher mortality, poor neurological outcome, and increased length of stay in the intensive care unit and hospital [1-5]. Greer et al. confirmed this 2008 in a meta-analysis of 14,431 patients with a variety of neuro- logical injuries [6]. Therefore, fever control plays a key role in therapy of patients with acute brain injury. Several therapeutic options are available to lower the body temperature. Primarily, antipyretic medication, physical cooling methods, and ice pads are applied. The next escalation step is the application of various surface or endovascular cooling devices. The infusion of cold saline could serve as an alternative or additional method for targeted temperature management. Although studies regarding the administration of cold saline for fever control appear reasonable [7-10], there are currently no new, reliable results. This is also due to the cumbersome application of infusions in order to achieve sufficient temperature control. There is no standardized load management regarding the administration of cold saline, and there are no closed-loop systems available based on continuous temperature-controlled feedback. Moreover, it is difficult to estimate the required amount of fluid to achieve normothermia merely on the basis of body weight. Besides, the subsequent long-term temperature stabilization via repetitive manual application of infusions would require substantial nursing time.

In this study, we present cases undergoing treatment based on a new automated infusion system for temperature control (tempedy $\AA$, seiratherm $\mathrm{GmbH}$, Herzogenaurach, Germany). Leveraging on the routine i.v. fluid application in intensive care units this stand-alone medical device adjusts flow rate and temperature of infusions in order to systemically adjust body core temperature, all controlled via feedback loop with standard temperature measuring probes. The primary purpose of this study was to evaluate the feasibility and safety of the new device, with special focus on the amount of fluid needed to achieve and maintain the target temperature. Secondly, the efficacy of the new device was examined, defined as the time and amount of fluid needed to reach and maintain the target temperature.

\section{Methods}

The study was approved by the ethics committee of Zurich, Switzerland, and consent was obtained from all patients or custodians. Between August 2015 and June 2017, a total of 12 patients were treated with the automated infusion device (tempedy®, seiratherm $\mathrm{GmbH}$, Herzogenaurach, Germany). Three patients suffered from subarachnoid hemorrhage, four from intracerebral hemorrhage, one from ischemic stroke, one from status epilepticus with PRES, one from septic shock, and two from meningoencephalitis. Inclusion criteria for 10 patients were intractable fever. Refractory fever was defined according to Badjatia et al., but adapted to local treatment standards, i.e., bladder temperature $\geq 37.9^{\circ} \mathrm{C}$, persistent at least 2 $\mathrm{h}$ after administration of antipyretic medication (acetaminophen, novaminsulfon, diclofenac), cold washing solutions, and $\AA$ ice packs [7]. Two patients were treated with tempedy immediately after termination of an endovascular cooling period, in order to maintain normothermia and to counter a temperature riseafter a long-term ${ }^{\circledR}$ hypothermia treatment (Fig. 1) 


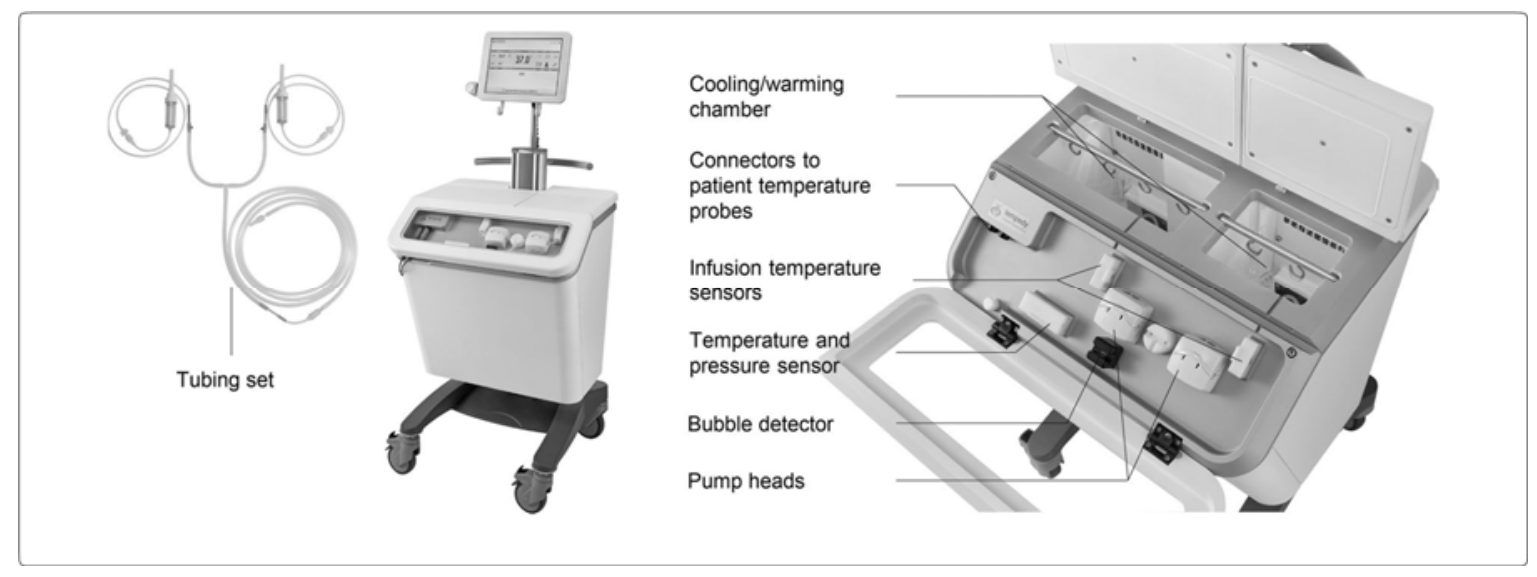

Fig. 1 tempedy ${ }^{\circledR}$ console and proprietary disposable (left) and top view of the two chambers, pumps, and sensor elements (right)

The tempedy console contains two separate separately tempered chambers in which the infusion solution bags are placed. The system can be used with any crystalloid solution according to the physician's discretion (saline, sodium lactate solutions, etc.). Each of the chambers is accurately tempered with Peltier elements, and the temperature of the infused fluid can range from 4 to $42{ }^{\circ} \mathrm{C}$. The chambers have a maximum liquid storage capacity of 6 $\mathrm{L}$. The infusion bags are interconnected with an application set which merges the fluid streams and leads them in a highly isolated line to the patient access point. This non-additionally invasive solution makes use of any existing venous access point with Luer lock such as an indwelling peripheral venous cannula or a central access. Two pumps pump the fluid into the patient's body, con- trolled by various sensors for temperature, pressure, and a bubble detector to ensure safety. Fluid infusion is performed by two peristaltic pumps, one for each chamber.

Individual flow rates, as well as the mixing ratio between the cold and warm fluid prior to application, are con- trolled by a proprietary algorithm, thereby enabling a controlled fluid infusion in the continuous range from 4 to $42^{\circ} \mathrm{C}$.

The system has a fully automated physiological feedback via temperature probes, suitable for different physiological measurement sites, and is controlled by a proprietary algorithm adjustable to each patient. The temperature measuring probe of the device in our patients was placed in the esophagus. Based on continuous body temperature measurements and physicians' treatment targets for fluid and temperature management, the system automatically modulates flow rate and temperature of infusions prior to the application. In case the patient's actual temperature is above a preset temperature threshold, the system will automatically infuse cooler fluids (down to $4{ }^{\circ} \mathrm{C}$ ) in order to achieve the required temperature reduction. There is no optimal or standardized duration of therapy for this device, as it strongly depends upon the patient specific characteristics and treatment targets set by the caregivers. This novel system is approved for clinical use in Europe via the CE mark, and it is also cleared for the USA with FDA approval.

With regard to our patients, the cooling system was set to automatic mode. Target temperatures were deter- mined for every patient individually, based on patient characteristics, indication, and treatment targets. Patient target temperatures ranged between 36.5 and 38.0 ${ }^{\circ} \mathrm{C}$, with a preset tolerance range of $0.5{ }^{\circ} \mathrm{C}$ for the first two patients and $0.2-0.3{ }^{\circ} \mathrm{C}$ for the others. The preset tolerance is an individually predefined patient body temperature range that allows for spontaneous temperature fluctuations within this range without triggering the device to infuse cooling fluids. Thus, if the user decides to preset a target temperature of $37.2{ }^{\circ} \mathrm{C}$ and 
a target temperature tolerance of $0.3^{\circ} \mathrm{C}$, temperature fluctuations between 37.2 and $37.5{ }^{\circ} \mathrm{C}$ will not trigger a device intervention.

The system is cleared for the usage of any intravenous infusion. In this study, however, Ringer's lactate was used in all patients. During the treatment with the device, the administration of cold washing solutions and ice packs was discontinued. The antipyretic medication was continued.

All patients were treated at the neurocritical care unit and undergoing daily chest X-rays, laboratory analyses and two-hourly blood gas analysis. The treating physicians were specially trained with regard to possible side effects of the new device such as pulmonary edema, cardiac events, or electrolyte disturbances due to potential fluid overload. Shivering was assessed hourly according to the Bedside Shivering Assessment Scale [10].

Data from patients treated for at least $12 \mathrm{~h}$ without interruption and with a preset tolerance of $0.2-0.3^{\circ} \mathrm{C}$ were analyzed.

\section{Results}

Of the 12 patients treated, four were excluded from the analysis: two due to the fact that treatment time was less than $12 \mathrm{~h}$ and two patients because the preset temperature tolerance of $0.5{ }^{\circ} \mathrm{C}$ did not meet the inclusion criteria (inclusion criteria preset tolerance $0.2-0.3{ }^{\circ} \mathrm{C}$ ). Patient characteristics are given in Table 1 . 
Table 1 Clinical and demographic characteristics of treated patients

\begin{tabular}{|c|c|c|c|c|c|c|c|c|c|c|}
\hline & Diagnosis & Age & Weight (kg) & Height $(\mathrm{cm})$ & $\begin{array}{l}\text { Included (U) } \\
\text { Excluded (E) }\end{array}$ & $\begin{array}{l}\text { Reason for exclu- } \\
\text { sion }\end{array}$ & $\begin{array}{l}\text { Outcome atICU } \\
\text { discharge GOS }\end{array}$ & $\begin{array}{l}\text { Treatment } \\
\text { duration } \\
\text { with tempedv'(h) }\end{array}$ & $\begin{array}{l}\text { Total infused fluid } \\
\text { by tempedv }(\mathrm{ml})\end{array}$ & $\begin{array}{l}\text { Initial temperature } \\
\text { before tempedv } \\
\text { application }\left({ }^{\circ} \mathrm{C}\right)\end{array}$ \\
\hline 1 & $\begin{array}{l}\text { Pneumococcal } \\
\text { meningitis }\end{array}$ & 64 & 60 & 169 & 1 & nja. & 1 & 41 & 7460 & 37.9 \\
\hline 2 & $\begin{array}{l}\text { SAH WFNSIV, Hunt } \\
\text { and Hess } 3\end{array}$ & 54 & 65 & 165 & 1 & $\mathrm{n} / \mathrm{a}$. & 3 & 16.25 & 3801 & $36.5^{*}$ \\
\hline \multirow[t]{2}{*}{3} & Ischemic stroke & 34 & 120 & 188 & 1 & $\mathrm{n} / \mathrm{a}$. & 1 & 20.25 & 4541 & 38.5 \\
\hline & $\begin{array}{l}\text { Status epilepticus } \\
\text { with PRES }\end{array}$ & 59 & 80 & 164 & I & $\mathrm{n} / \mathrm{a}$. & 3 & 88.5 & 5703 & 37.9 \\
\hline \multirow[t]{2}{*}{5} & Septic Shock & 29 & 65 & 175 & 1 & $\mathrm{n} / \mathrm{a}$. & 4 & 40.25 & 3226 & 38.2 \\
\hline & $\begin{array}{l}\text { SAH WFNS V, Hunt } \\
\text { and Hess } 4\end{array}$ & 56 & 70 & 165 & 1 & $\mathrm{n} / \mathrm{a}$. & 3 & 26 & 4756 & 39.3 \\
\hline \multirow[t]{2}{*}{7} & $\mathrm{ICH}$ & 46 & 80 & 176 & 1 & $\mathrm{n} / \mathrm{a}$. & 3 & 48.75 & 6579 & 39.5 \\
\hline & Meningitis & 38 & 90 & 173 & E & $\begin{array}{l}\text { Preset tolerance } \\
0.5^{\circ} \mathrm{C} \text {, treatment } \\
\text { time }<12 \mathrm{~h}\end{array}$ & 2 & 9.5 & 3675 & 39.2 \\
\hline 9 & $\mathrm{ICH}$ & 46 & 90 & 165 & I & $\mathrm{n} / \mathrm{a}$. & 2 & 141.75 & 7557 & $36.6^{*}$ \\
\hline 10 & $\begin{array}{l}\text { SAH WFNS V, Hunt } \\
\text { and Hess } 5\end{array}$ & 65 & 55 & 165 & E & $\begin{array}{l}\text { Preset tolerance } \\
0.5^{\circ} \mathrm{C}\end{array}$ & 3 & 29 & 2471 & 37.9 \\
\hline 11 & $\mathrm{ICH}$ & 51 & 95 & 182 & E & $\begin{array}{l}\text { Treatment time } \\
<12 \mathrm{~h}\end{array}$ & 3 & 3 & 1573 & 38.5 \\
\hline 12 & $\mathrm{ICH}$ & 64 & 65 & 165 & E & $\begin{array}{l}\text { Treatment time } \\
<12 \mathrm{~h}\end{array}$ & 3 & 5 & 3301 & 39.2 \\
\hline
\end{tabular}

GOS Glasgow Outcome Scale, ICH intracerebral hemorrhage, ICU intensive care unit, PRES posterior reversible encephalopathy syndrome, SAH subarachnoid hemorrhage, WFNS World Federation of Neurosurgical Societies

-Treated with tempedx after a previous endovascular cooling | 
Data from eight patients, four men and four women, were analyzed (mean age $48.5 \pm 12$ years, body weight $78.8 \pm 19 \mathrm{~kg}$ and height $171 \pm 8 \mathrm{~cm}$ ). Seven of the eight patients had an endotracheal intubation and were mechanically ventilated. The origin of fever was infectious, indicated by the detection of microorganisms in the urine, cerebrospinal fluid, or blood, or signs of pulmonary infiltration in chest X-ray $(n=4)$, or suggested to be so due to a systemic inflammatory response with cerebral vasospasm $(n=4)$.

The mean duration of application of the cooling device was $53 \mathrm{~h}$ (range from $16 \mathrm{~h}$ to $142 \mathrm{~h}$ ). The mean time to reach the target temperature was $73 \mathrm{~min}$ (range from $15 \mathrm{~min}$ to $330 \mathrm{~min}$ ). The amount of fluid applied is summarized in Table $\underline{2}$.

\begin{tabular}{|c|c|c|c|c|c|c|}
\hline & \multicolumn{2}{|c|}{$\begin{array}{l}\text { Amount of fluid infused to reach } \\
\text { target temperature }(n=8)\end{array}$} & \multicolumn{2}{|c|}{$\begin{array}{l}\text { Amount of fluid infused in first } 12 \mathrm{~h} \\
(n=8)\end{array}$} & \multicolumn{2}{|c|}{$\begin{array}{l}\text { Amount of fluid infused in firs } \\
24 \mathrm{~h}(n=6)\end{array}$} \\
\hline & Mean & (SD) & Mean & (SD) & Mean & (SD) \\
\hline \multirow[t]{2}{*}{ Via tempedy ${ }^{\ominus}$} & $1650 \mathrm{ml}$ & $(2260 \mathrm{ml})$ & $2940 \mathrm{ml}$ & $(1850 \mathrm{ml})$ & $4030 \mathrm{ml}$ & $(2190 \mathrm{ml})$ \\
\hline & $21.2 \mathrm{ml} / \mathrm{kg}$ & $(28.5 \mathrm{~m} / \mathrm{kg})$ & $40.9 \mathrm{~m} / \mathrm{kg}$ & $(26.2 \mathrm{~m} / \mathrm{kg})$ & $57.4 \mathrm{ml} / \mathrm{kg}$ & $(33.1 \mathrm{ml} / \mathrm{kg})$ \\
\hline \multirow[t]{2}{*}{ In parallel to device } & $<100 \mathrm{ml}$ & $<100 \mathrm{ml}$ & $1460 \mathrm{ml}$ & $(320 \mathrm{ml})$ & $3300 \mathrm{ml}$ & $(720 \mathrm{ml})$ \\
\hline & $<100 \mathrm{ml}$ & $<100 \mathrm{ml}$ & $19.2 \mathrm{~m} / \mathrm{kg}$ & $(5.8 \mathrm{~m} / \mathrm{kg})$ & $45.9 \mathrm{ml} / \mathrm{kg}$ & $(14.3 \mathrm{ml} / \mathrm{kg})$ \\
\hline Fluid balance & $\mathrm{n} / \mathrm{a}$. & $\mathrm{n} / \mathrm{a}$. & $1350 \mathrm{ml}$ & $(1550 \mathrm{ml})$ & $1960 \mathrm{ml}$ & $(1880 \mathrm{ml})$ \\
\hline
\end{tabular}

In the first $12 \mathrm{~h}, 89.4 \%$ of the time temperature values were in the target range (median $95.3 \%$, range $83.8-100 \%)$. The mean cooling speed was $1.3^{\circ} \mathrm{C} / \mathrm{h}\left( \pm 1.0^{\circ} \mathrm{C} / \mathrm{h}\right)$ and the mean amount of fluid needed to reduce the temperature by $1{ }^{\circ} \mathrm{C}$ was $18.7 \mathrm{ml} / \mathrm{kg}$ body weight $( \pm 11.0 \mathrm{ml} / \mathrm{kg}$ body weight, median $13.1 \mathrm{ml} / \mathrm{kg} \circledR$ body weight). For the six patients treated with tempedy for $24 \mathrm{~h}$ or longer the table shows that a relatively higher fluid load was required within the first 12 $\mathrm{h}$ to reach the target temperature. However, with sustained fever therapy and ongoing normothermia stabilization, the fluid application was significantly reduced. The installation of the cooling device did not cause any technical difficulties. No clinical signs of fluid overload such as an acute pulmonary edema occurred. Also, we observed no clinically relevant electrolyte disturbances or acid-base dysfunction. To further illustrate the functionality of the new device, we illustrate the course of two patients with different indications for target temperature management. 
Figure $\underline{2}$ shows the temperature profile of a patient with intract $₫$ able fever and the amount of fluids infused by tempedy, starting with an esophageal temperature of $38.2{ }^{\circ} \mathrm{C}$. A target temperature of $37.5{ }^{\circ} \mathrm{C}$ with a tolerance of $+0.2{ }^{\circ} \mathrm{C}$ was determined. After infusion of two boluses of cold saline (overall $538 \mathrm{ml}, 8.3 \mathrm{ml} / \mathrm{kg}$ body weight), the patient reached the target temperature. During the following $4 \mathrm{~h}$, the patient repeatedly developed fever. Due to the preset limits for fluid infusion and the closed-loop system, the device applied further boluses of cold fluid. After $4.5 \mathrm{~h}$ the patient reached a stable condition with normothermia and no further need of cold fluids. In fact, for the next $7 \mathrm{~h}$ the esophageal temperature continually decreased which suggests a confirmation of an effect previously reported by Rajek et al. [8]. This subsequent decline is most likely due to the reduction of both the total body heat content and the core metabolic rate. For this case, the total amount of fluids infused by the device in the first $12 \mathrm{~h}$ was $3195 \mathrm{ml}$. In parallel to the device, the patient received a further $1200 \mathrm{ml}$ of fluid infusions within the first $12 \mathrm{~h}$. Taking the diuresis of the patient into account, after $12 \mathrm{~h}$ the total fluid balance was $445 \mathrm{ml}$.

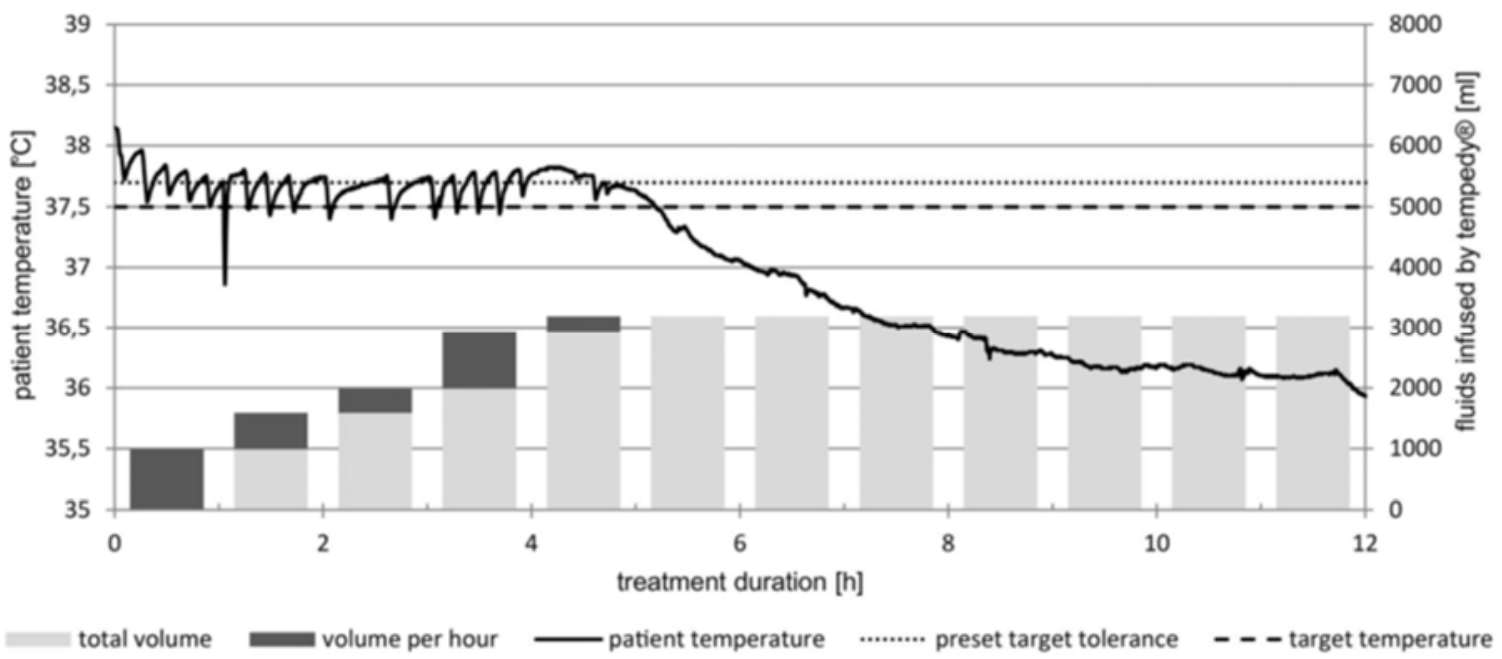

Fig. 2 Temperature profile and amount of fluids infused in a single patient with intractable fever of $38.2^{\circ} \mathrm{C}$ 
Figure $\underline{\mathbf{3}}$ depicts the temperature profile of a patient who was initially treated for several days with an endovascular cooling device to induce hypothermia.

Due to the increased risk of an additional thromboembolic event during long-term application of intravascular catheters, the patient was switched over to the tempedy ${ }^{\circledR}$ device for the subsequent temperature stabilization, starting with a temperature of $36.2{ }^{\circ} \mathrm{C}$. The target temperature too was $36.2{ }^{\circ} \mathrm{C}$ with a tolerance of $0.2^{\circ} \mathrm{C}$.

With an initial bolus of $200 \mathrm{ml}$ cold saline, the patient reached the target temperature but repeatedly developed temperatures above the defined target during the following $10 \mathrm{~h}$. The device reacted with repeated infusions of boluses of cold saline. To maintain the target temperature, the patient received $3601 \mathrm{ml}$ of cold fluids within $12 \mathrm{~h}$ and an additional amount of $990 \mathrm{ml}$ was infused in parallel to the device. Taking the diuresis into account, the total fluid balance over the first $12 \mathrm{~h}$ was $991 \mathrm{ml}$.

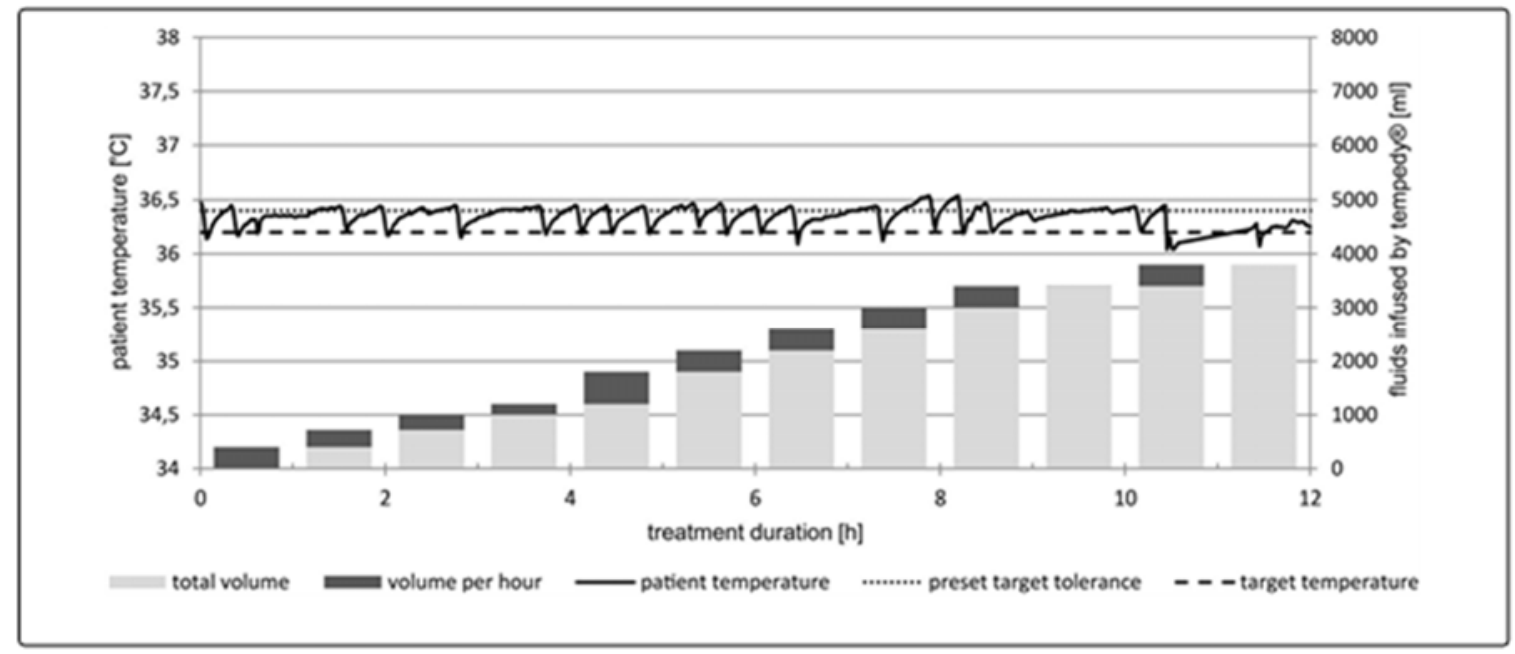

Fig. 3 Temperature profile of a patient treated to maintain normothermia after previous endovascular cooling

\section{Discussion}

The analysis of this small patient series was performed to determine the safety, feasibility, and efficacy of a new automated infusion cooling device for target temperature management. In our findings the median time to target temperature was $15 \mathrm{~min}$ and the median amount of fluid to target temperature was $540 \mathrm{ml}, 8 \mathrm{ml} / \mathrm{kg}$ body weight, respectively. The median amount of fluid applied to maintain the target temperature during the first $12 \mathrm{~h}$ was $2040 \mathrm{ml}, 25 \mathrm{ml} / \mathrm{kg}$ body weight, respectively. Taking the diuresis into account, the median total fluid balance in the first $12 \mathrm{~h}$ was $961 \mathrm{ml}$.

Furthermore, our data indicate that due to the fever reduction to normothermic levels, the fluid load was initially higher, whereas the subsequent normothermia maintenance required less. This leads to a slightly positive fluid balance for the first $12 \mathrm{~h}$. However, over the whole course of treatment we observed the following effects: firstly, the device required less fluids for the subsequent normothermia stabilization, and secondly, some patients had a transiently increased diuresis; consequently, the initially observed slightly positive fluid balance was reduced toward a neutral fluid balance. Besides the fluids that were applied by the device, further fluids were infused in parallel (the application of drugs, nutrition, etc.). Within the first $12 \mathrm{~h}, 66 \%$ of the overall fluid load was cooling fluids applied via the device. Hence, the overall 
fluid application could potentially be further reduced by applying a higher percentage of fluids via the device. seiratherm $\mathrm{GmbH}$ is currently working on developing an extension that also allows the infusion of col- loids, blood-based products, and nutrition solutions.

No serious adverse events such as pulmonary edema were observed. This has also been observed in other study groups using larger fluid amounts for hypothermia induction [11]. Neither did we observe shivering, most likely as a result of 11 of 12 patients being under deep analgosedation due to the severity of their disease. One patient received standard medication only for analgesia (morphine, acetaminophen, novaminsulfon). In patients with acute brain injury, pyrexia has been identified as an independent risk factor for increased mortality and poorer neurological outcome $[\underline{5}, \underline{6}, \underline{12}, \underline{13}$. Even though the relationship is proven, and fever control is highly recommended, there is a lack of recommendation on how to reach and maintain normothermia. Several therapeutic options are available for fever treatment. Primarily, antipyretic medication and physical cooling methods are applied. Antipyretics, such as, acetaminophen, metamizole, and non-steroidal anti-inflammatory drugs act on the hypothalamic set point. In brain-injured patients, the integrity of the thermoregulatory system is rarely given. Therefore, antipyretic agents alone are usually ineffective for fever treatment [5]. In the PAIS trial, $6 \mathrm{~g} /$ day acetaminophen in stroke patients resulted in a mean body temperature reduction of only $0.26{ }^{\circ} \mathrm{C}$ compared to placebo, and the study could not report an improved outcome for treatment with acetaminophen [14]. Some pharmacologic interventions are even potentially harmful, e.g., parenteral diclofenac infusion might decrease brain tissue oxygen tension in aneurysmal subarachnoid hemorrhage [15].

The next escalation step after antipyretic medication for fever treatment is the application of various surface or endovascular cooling devices. Both systems have been shown to be effective in inducing and maintaining normothermia for prolonged periods [16]. Cooling with water or air circulating blankets is usually preferred for fever control, while endovascular methods, due to the risk of thromboembolic complications, are more commonly restricted to therapeutic hypothermia [17]. Both systems use a continuous feedback algorithm based on continuous patient temperature assessment. Water at a specific temperature, based on the prescribed, programmed mode of therapy and the patient's current temperature, is circulating through cooling pads attached to the skin or through endovascular catheters. Newer data show that endovascular cooling has advantages over surface cooling when it comes to induction speed, stability and temperature control, overshoot avoidance, working load for medical personal and rewarming control [18]. Although both systems are proven to be most effective, their disadvantages have to be taken into account. Both systems are quite costly and require a certain work load and time for installation. Frequently, anti-shivering therapy is needed. With surface cooling, there is the risk of skin lesions. Furthermore, endovascular cooling contains the risk of mechanical complications due to the catheter insert and the risk of central venous line infections [19]. In addition, there is a documented increased thromboembolic risk due to the intravascular catheter [17]. Therefore, especially for fever reduction, noninvasive and more cost-effective methods should be the first choice. In 2006, Badjatia et al. showed that the application of boluses with cold salines represents a safe, feasible, and inexpensive method to achieve normothermia in patients with refractory fever [7]. Patients still suffering from refractory fever $>38{ }^{\circ} \mathrm{C}$ more than $2 \mathrm{~h}$ after the administration of acetaminophen $(650 \mathrm{mg}$ orally) and placement of a water-circulating cooling blanket were treated with a bolus of cold saline (mean $29.2 \mathrm{ml} / \mathrm{Kg}$ ). With the infusion of cold saline, all patients reached nor- mothermia. Moreover, it was also possible to maintain normothermia for the next $24 \mathrm{~h}$. Although the study postulated that the maintenance of normothermia was likely to be attributed to the continued use of surface cooling with water-circulating blankets, the achievement of normothermia was most likely due to the effect of the cold saline bolus. Even earlier, Rajek et al. already quantified the cooling effects of cold infusions and investigated the higher than expected reduction in core temperatures [8]. This study measured core and peripheral tissue temperatures as well 
as energy expenditure in healthy volunteers before and after infusion of $4{ }^{\circ} \mathrm{C}$ fluid, and was able to conclude and quantify that the reduced core temperature resulted from three factors: (1) $50-55 \%$ from the systemic cooling effects of the actual fluids, (2) ca. $30 \%$ from the fact that the reduction in core heat content remained partially constrained to core tissues, and (3) 10 $20 \%$ from the fact that the cutaneous heat loss exceeded metabolic heat production.

This also explains the advantage of cold saline over surface cooling. The infusion of cold saline reduces core temperatures not only by reduction of the core metabolic rate and total body heat content but also by isolating the core and peripheral thermal compartments. The major potential disadvantage of the new method is a risk of fluid overload, potentially leading to cardiac and respiratory failure with imminent pulmonary edema [20]. Whereas in sepsis additional fluids might be beneficial [11], special caution should be used in elderly patients with frequently occurring latent heart failure or in all patients with cardiac or renal disease and reduced urinary output. Thus, it seems reasonable to try to achieve the target temperature with the least possible amount of fluid. Therefore, the temperature of the fluid that actually enters the patient should be as close to the recommended $4{ }^{\circ} \mathrm{C}$ as possible [9]. To date, the cold saline for infusion is kept in a refrigerator before being administered to the patient. At the bedside there usually is an interruption of the cooling chain; thus, the temperature of the cold saline administered to the patient ${ }^{\circledR}$ is more likely to be $10-15{ }^{\circ} \mathrm{C}$ than $4{ }^{\circ} \mathrm{C}$. In our tempedy test series the temperature sensor in the tubing set showed an average infusion temperature of $4-5{ }^{\circ} \mathrm{C}$. Compared to the manual application of refrigerated saline for fever therapy [5], this system offers three advantages. First, the device increases effectiveness as the infusion temperature remains stable throughout the application. Second, the amount of infused fluid is deter- mined for every patient individually and applied patient adaptive in order to reduce burden. Third, the device enables active pumping and precise flow rates which appears to be of advantage compared to simple drip infusion or application by pressure cuffs. In summary, this could explain why we needed smaller amounts of fluid to reach normothermia in the initial phase of fever reduction in comparison to the fluid requirements the Badjatia study.

The study has several strong limitations: The number of patients was small, and there was a substantial heterogeneity regarding the treatment periods. Side effects of long-term treatment cannot be excluded. Furthermore, antipyretic medication was continued. Synergistic effects with the physical cooling are highly probable, as antipyretics prevent hypothalamic counter regulation. Another limitation is the fact that the software was continually improved throughout the course of patient enrollment. The first patients were treated with a first software release, whereas the next software updates implemented some improvements regarding the feedback algorithm. Consequently, it could be postulated that the first treatments lacked the benefit of the technical optimum, but we consider this effect to be acceptable for this study analysis.

\section{Conclusion}

In our small pilot study we showed the feasibility and efficacy of the tempedy cooling device. Although we pro- vided first data regarding safety, there is the potential risk of fluid overload. However, the new closed-loop temperature feedback, the stability of the temperature of the infused fluid, and the individualized settings reduce the risk of fluid overload compared to manual administration. Further controlled randomized studies are needed to evaluate the longtime safety, as well as the best indications and timing for this cooling device. 


\section{References}

1. Marion DW. Controlled normothermia in neurologic intensive care. Crit Care Med. 2004;32(2 Suppl.):S43-5.

2. Rincon F, Hunter K, Schorr C, Dellinger RP, Zanotti-Cavazzoni S. The epidemiology of spontaneous fever and hypothermia on admission of brain injury patients to intensive care units: a multicenter cohort study. J Neurosurg. 2014;121:950-60.

3. Kilpatrick MM, Lowry DW, Firlik AD, et al. Hyperthermia in the neuro- surgical intensive care unit. Neurosurgery. 2000;47:850-5 (discussion 855-856).

4. Diringer MN, Reaven NL, Funk SE, Uman GC. Elevated body temperature independently contributes to increased length of stay in neurologic intensive care unit patients. Crit Care Med. 2004;32:1489-95.

5. Badjatia N. Hyperthermia and fever control in brain injury. Crit Care Med. 2009;37:250-7.

6. Greer DM, Funk SE, Reaven NL, Ouzounelli M, Uman GC. Impact of fever on outcome in patients with stroke and neurologic injury: a comprehensive meta-analysis. Stroke. 2008;39(11):3029-35.

7. Badjatia N, Bodock M, Guanci M, et al. Rapid infusion of cold saline (4 ${ }^{\circ}$ ) as adjunctive treatment of fever in patients with brain injury. Neurology. 2006;66:1739-41. Rajek A, Greif $\mathrm{R}$, Sessler DI, et al. Core cooling by central venous infusion of ice-cold (4 degrees $C$ and 20 degrees C) fluid: isolation of core and peripheral thermal compartments. Anesthesiology. 2000;93:629-37.

8. Fluher J, Markota A, Stozer A, Sinkovic A. Optimization of induction of mild therapeutic hypothermia with cold saline infusion: a laboratory experiment. Bosn J Basic Med Sci. 2015;15(4):60-3.

9. Badjatia N, Strongilis E, Gordon E, Prescutti M, Fernandez L, Fernandez A, Buitrago M, Schmidt JM, Ostapkovich ND, Mayer SA. Metabolic impact of shivering during therapeutic temperature modulation: the Bedside Shivering Assessment Scale. Stroke. 2008;39(12):3242-7.

10. Rochwerg B, Alhazzani W, Sindi A, Heels-Ansdell D, Thabane L, Fox- Robichaud A, Mbuagbaw L, Szczeklik W, Alshamsi F, Altayyar S, Ip WC, Li G, Wang M, Wludarcyk A, Zhou Q, Guyatt GH, Cook DJ, Jaeschke R,

11. Annane D, Fluids in Sepsis and Septic Shock Group. Fluid resuscitation in sepsis: a systematic review and network meta-analysis. Ann Intern Med. 2014;161(5):347-55.

12. Broessner G, Beer R, Lackner P, Helbok R, Fischer M, Pfausler B, Rhorer J, KuppersTiedt L, Schneider D, Schmutzhard E. Prophylactic, endovasculary based, long-term normothermia in ICU patients with severe cerebrovascular disease: bicenter prospective, randomized trial. Stroke. 2009;40(12):e657-65.

13. Broessner G, Lackner P, Fischer M, Beer R, Helbok R, Pfausler B, Schneider D, Schmutzhard E. Influence of prophylactic, endovasculary based normothermia on inflammation in ICU patients with severe cerebrovascular disease: a prospective, randomized trial. Stroke. 2010;41(12):2969-72.

14. Den Hertog HM, van der Worp HB, van Gemert HM, Algra A, Kappelle LJ, van Gijn J, Koudstaal PJ, Dippel DW, PAIS Investigators. The Paracetamol (Acetaminophen) in Stroke (PAIS) trial: a multicentre, randomised, placebo-controlled, phase III trial. Lancet Neurol. 2009;8(5):434-40. 
15. Schiefecker AJ, Pfausler B, Beer R, Sohm F, Sabo J, Knauseder V, Fischer M, Dietmann A, Hackkl WO, Thome C, Schmutzhard E, Helbok R. Parenteral diclofenac infusion significantly decreases brain-tissue oxygen tension in patients with poor-grade aneurysmal subarachnoid haemorrhage. Crit Care. 2013;17(3):R88.

16. Deye N, Cariou A, Girardie P, Pichon N, Megarbane B, Midez P, Tonnelier JM, Boulain T, Outin H, Delahaye A, Cravoisy A, Mercat A, Blanc P, Santre C, Quintard H, Brivet F, Charpentier J, Garrigue D, Salengro R, Francois B, Quenot JP, Vincent F, Gueugniaud PY, Mira JP, Carli P, Vicaut E, Baud FJ. Endovascular versus external targeted temperature management for patients with out-of-hospital cardiac arrest: a randomized, controlled study. Circulation. 2015;132:182-93.

17. Müller A, Lorenz A, Seifert B, Keller E. Risk of thromboembolic events with endovascular cooling Catheters in patients with subarachnoid hemor- rhage. Neurocrit Care. 2014;21:207-10.

18. Polderman $\mathrm{KH}$, Herold I. Therapeutic hypothermia and controlled normo- thermia in the intensive care unit: practical considerations, side effects and cooling methods. Crit Care Med. 2009;37(3):1101-20.

19. Polderman $\mathrm{KH}$. How to stay cool in the intensive care unit? Endovascular versus surface cooling. Circulation. 2015;132(3):152-7.

20. Kim F, Nichol G, Maynard C, Hallstrom A, Kudenchuk PJ, Rea T, et al. Effect of prehospital induction of mild hypothermia on survival and neurologi- cal status among adults with cardiac arrest. A randomized clinical trial. JAMA. 2014;311(1):45-52. 